\title{
Una vida al servicio de la Hacienda. Transitar el oficio entre la colonia y la revolución
}

\author{
A life in the service of the Treasury. Transit the trade between the colony and the \\ revolution
}

Bárbara M. Aramendi

barbara_aramendi@yahoo.com.ar

Universidad Nacional de Salta-CONICET, Argentina

Recepción: 15 Septiembre 2021

Aprobación: 14 Octubre 2021

Publicación: 01 Noviembre 2021

Cita sugerida: Aramendi, B.M. (2021). Una vida al servicio de la Hacienda. Transitar el oficio entre la colonia y la revolución. Anuario del Instituto de Historia Argentina, 21(2), e153.

https://doi.org/10.24215/2314257Xe153
Resumen: En el presente trabajo abordamos la trayectoria y el accionar de Antonio Atienza, en su calidad de oficial de la Hacienda en Salta desde fines del siglo XVIII hasta los primeros años de la etapa revolucionaria. Indagamos sobre su desempeño profesional, las relaciones que construyó y los conflictos en los cuales estuvo involucrado. Apelamos así al abordaje de la institución de la Hacienda a partir de uno de sus integrantes, analizando su origen, formación y contratación, así como las relaciones que tejió, para comprender las características y especificidades de las prácticas en la Hacienda del espacio analizado. La fuerte identificación del oficial con su empleo se mantuvo a través de toda su vida, incluso en los difíciles momentos revolucionarios, lo que nos señala toda una existencia signada por la actividad profesional.

Palabras clave: Oficial de Hacienda, Trayectoria, Relaciones, Tucumán.

Abstract: In this paper we address the trajectory and actions of Antonio Atienza, as an official of the Treasury in Salta from the late eighteenth century until the early years of the revolutionary period. We inquired about his professional performance, the relationships he built and the conflicts in which he was involved. In this way, we have appealed to approach the institution of the Hacienda from the perspective of one of its members, inquiring about its origin, formation and hiring, as well as the relationships that he weaved in order to understand the characteristics and specificities of the practices in the Hacienda of the analyzed space. The officer's strong identification with his job was maintained throughout his life, even during the difficult revolutionary times, which shows us a whole life marked by professional activity.

Keywords: Treasury officer, Trajectory, Relationships, Tucumán.

"En esta época, descuella en Salta otro artista, dedicado éste a la música: don Antonio de Atienza y Picazo, español peninsular que vino a la Intendencia como oficial mayor de las cajas de real hacienda y que compuso contradanzas que no han llegado hasta nosotros".

Acevedo (1965, p. 420) 


\section{INTRODUCCIÓN}

Colocar como protagonistas de los procesos históricos a los individuos, a los actores efectivos, sus motivaciones e interacciones estratégicas con el ambiente que los rodea es una opción metodológica que nos sitúa en una historia de cerca. ${ }^{1}$ El valor de examinar la vida de una persona no radica en la construcción de una narración coherente de una secuencia significante y orientada de acontecimientos que presenten la experiencia como una unidad y totalidad, sino en el de pensar lo real con sus discontinuidades y yuxtaposiciones aleatorias, y hacerlo en términos relacionales. En términos de trayectoria, la noción invita a analizar una serie de posiciones ocupadas sucesivamente por el mismo agente en un espacio en movimiento y sometido a transformaciones (Bourdieu, 1997).

La trayectoria que presentamos de Antonio Atienza, oficial primero de la Real Hacienda de Salta, debe ser contextualizada dentro del Antiguo Régimen, en el que los vínculos sociales entre la persona y la sociedad que la rodeaba procuraban apoyo, capital relacional y capacidad de acción que los agentes podían movilizar en su favor. ${ }^{2}$ En este sentido, son centrales los aportes de equipos de trabajo que incluyen a José María Imízcoz (1996, 2001) y Jean Pierre Dedieu (2000), que se abocaron al estudio de la administración de la monarquía hispana abrevando en el análisis microhistórico de las redes sociales para comprender la inserción de grupos familiares dentro del aparato institucional del Antiguo Régimen. Dentro de este paradigma Michel Bertrand (2011) realizó un estudio sistemático de los cuerpos de oficiales de la Real Hacienda de Nueva España en los siglos XVII y XVIII, y profundizó en el mundo personal, social y profesional de los implicados. ${ }^{3}$

Dentro del imperio español, la administración era la columna vertebral que daba vida a un sinfín de redes potenciales, fuente de distinciones, títulos y cargos que los diferentes actores trataban de acaparar. El patronazgo y el clientelismo eran el núcleo medular de las relaciones de poder en la corte y también en el ámbito de las elites provinciales y municipales. Constituían un vínculo particularmente significativo de la articulación política y social. La Hacienda, sector administrativo estratégico, se constituía como un espacio relacional en el cual confluían autoridades políticas de diversas jerarquías, élites locales y hombres de negocios. Privilegiando la observación sobre diversos tipos de agentes, políticos y privados, en los últimos años una serie de estudios se han preocupado por el análisis de la Real Hacienda de la monarquía en el largo siglo XVIII, su significado y su existencia, y para ello consideraron este objeto de estudio en su calidad de espacio político, social y de negociación (Bertrand y Moutoukias, 2018; Dubet y Solbes Ferri, 2015, 2016).

El recorrido de ciertos hechos en la vida del oficial primero de las cajas de Salta nos permitirá recorrer el análisis de una Hacienda signada por el peso de unas reformas que se imponen con fuerza en los finales del siglo XVIII hasta los momentos en los que el período revolucionario pone su cuota de incertidumbre en un contexto signado por la guerra. Indagaremos así sobre su desempeño profesional, las relaciones que construyó y los conflictos en los cuales estuvo involucrado, para comprender las características y especificidades de las prácticas en la Hacienda del espacio analizado. El caso refleja situaciones significativas vividas por un representante del rey en los contextos mencionados: a fines del período colonial, se enfrenta con los poderes locales de la ciudad de Tucumán, y durante la revolución, cuando le es denegada la carta de ciudadanía. Esto nos permite observar la fuerte identificación que Atienza tuvo con su empleo a través de toda su vida, incluso en los difíciles momentos del momento independentista, lo que nos señala toda una existencia signada por la actividad profesional.

Apelamos al estudio de las agencias que muestran el vínculo entre el gobierno de los hombres y las instituciones en su historicidad (Barriera, 2014, p. 246), al abordaje de la institución de la Hacienda a partir de los aspectos que involucran a un nombre propio, su origen, formación y contratación, así como 
las relaciones que tejió con su ambiente y con las elites locales, lo cual a su vez constituye una empresa que permite comprender la especificidad y variedad de la realidad administrativa americana (Bertrand, 2011, pp. 167 y 168). En este caso, a diferencia de la mayoría de los trabajos que abordan la problemática, nuestro protagonista es un oficial menor actuante en una Hacienda local de un espacio periférico de la monarquía. Teniendo en cuenta este dato, que no es menor, consideramos que ciertas conclusiones a las que se ha arribado a través del estudio de oficiales de mayor jerarquía, con trayectorias y oportunidades diferentes, no pueden ser directamente extrapoladas al universo de un oficial subalterno cuya vida podía ser diametralmente opuesta a la de sus superiores. Al mismo tiempo, el espacio que nos convoca reviste una particularidad específica por su lugar marginal respecto de los centros de poder, lo cual nos brinda la oportunidad de comprender la monarquía en su totalidad desde las prácticas existentes en los márgenes (Das y Poole, 2008).

\section{La Hacienda en Salta del Tucumán}

Inmediatamente después de la llegada de Colón a América, la Corona tomó intervención en la administración económica y financiera de los territorios del nuevo mundo. Una de las primeras instituciones instaladas fue la Real Hacienda, que basaba su sistema de funcionamiento en una red de cajas recaudadoras que abarcaron jurisdiccionalmente todos los territorios indianos. Cada caja real, dependiendo de sus necesidades, del espacio donde se encontraban situadas y de su evolución en el tiempo, contó con una cantidad variable de oficiales, que habitualmente oscilaba entre dos y cuatro. Primigeniamente, las cajas estaban a cargo de un tesorero, un contador, un factor y un veedor; estos dos últimos cargos pronto desaparecieron mientras que los otros dos permanecieron durante todo el período colonial. Las principales, situadas en las capitales virreinales y en las cabeceras de circunscripciones administrativas menores, estaban bajo el mando colegiado del tesorero y el contador, que tenían responsabilidades conjuntas sobre sus actos (Emilliani, 1994). Mientras que en cada ciudad subalterna, el manejo de las cajas llamadas menores estuvo a cargo de un teniente tesorero nombrado por sus superiores. Para ayudar en sus tareas al tesorero y contador hubo empleados de distintas categorías y para distintos fines, oficios técnicos y subalternos; en las cajas de menor entidad, los deberes se concentraban en unos pocos oficiales.

Durante el siglo XVIII lo más importante de la reforma fue la nueva organización de la Hacienda: se quiso regularizar y mejorar la administración fiscal imponiendo reglas más precisas y un control más estricto en el manejo y percepción de los fondos. Los intendentes fueron el engranaje principal de este cambio pues se les dio la dirección de la Real Hacienda. Todos los oficiales reales dependían de ellos en lo relativo a las tareas administrativas y del Tribunal Mayor de Cuentas respecto a la aprobación de sus gestiones fiscales. Las cajas reales de todo el virreinato se convirtieron en tesorerías y contadurías de Real Hacienda, y los oficiales reales pasaron a denominarse ministros con obligación de recaudar y administrar los recursos fiscales que estuvieran a su cuidado, pero sin las facultades judiciales que habían tenido hasta entonces (Emilliani, 1994). Sin embargo, Alejandro Wayar (2010), en su estudio sobre la Real Hacienda tardocolonial, señala que las reformas fracasaron en su objetivo de incrementar el control sobre los recursos fiscales de sus dominios. ${ }^{4}$ Para el caso del Tucumán, refleja el incumplimiento de las cajas en el envío de sus excedentes, las desavenencias entre los empleados de la Hacienda y las corporaciones locales, y la dificultad de la Corona de implementar reformas administrativas profundas sin entrar en negociaciones con aquellos que se veían afectados por ellas.

La Gobernación del Tucumán formaba parte del Virreinato del Perú y jurídicamente estaba incluida en el distrito de la Audiencia de Charcas. Componían esta gobernación las ciudades de Jujuy, Salta, Tucumán, Santiago del Estero, Catamarca, La Rioja y Córdoba, lo que implicaba un territorio muy dilatado. Funcionaba allí una caja principal de Hacienda de la cual dependían las cajas menores del resto de las ciudades que comprendían la gobernación. Con la implementación de la Ordenanza de Intendentes del Río de la Plata en 1782 se introdujo en el flamante Virreinato del Río de la Plata la reorganización del territorio: la Gobernación del Tucumán se desmembró en dos Gobernaciones Intendencias, la de Salta del Tucumán y la de Córdoba del 
Tucumán. De esta manera, el territorio quedó organizado en un triple nivel jerárquico entre ciudades: capital virreinal, capital de Intendencia, ciudades subordinadas. Las ciudades subordinadas a la capital de la nueva Intendencia fueron San Salvador de Jujuy, San Miguel de Tucumán, San Fernando del Valle de Catamarca y Santiago del Estero, cada una como sede de una subdelegación. ${ }^{5}$

Hasta 1784 la caja estuvo ubicada en Jujuy, cuando fue trasladada a Salta, capital de la nueva Intendencia. A pesar de los problemas observados, la Intendencia incrementó sus ingresos gracias a la recuperación económica que experimentó el espacio surandino durante las últimas décadas del siglo XVIII; sin embargo, los gastos crecieron a un nivel superior (Wayar, 2010). Eran entonces los ministros propietarios el tesorero Gabriel Güemes Montero y el contador Joseph González de Prada. A su servicio, como oficial primero, desempeñaba el cargo Antonio de Atienza.

\section{Antonio de Atienza y Picazo}

Antonio Atienza y Picazo era peninsular, nacido en Tarazona de La Mancha, obispado de Cuenca, en 1763. Era hijo de Antonio Bernardo Atienza, regidor alguacil mayor hereditario de dicha villa, y de Juana Ramona Picazo, y fue criado por sus tíos María de los Dolores Domínguez y Juan Felipe Gómez en Cádiz. ${ }^{6}$ Según su relación de méritos y servicios, era de familia noble y distinguida, de las principales de su pueblo. ${ }^{7}$

Llegó a América en 1784, como oficial sexto de la Contaduría General de Propios y Arbitrios erigida en Buenos Aires; ${ }^{8}$ la plaza fue suprimida en ese mismo año, por lo cual continuó como entretenido en dicha contaduría. A principios de 1785 fue comisionado por el intendente de Buenos Aires, Francisco de Paula Sanz, para intervenir en la subasta de cueros pertenecientes a los pueblos de Misiones, función en la que estuvo durante más de nueve meses "[... y la desempeñó con la mayor integridad, sin embargo de las oposiciones que ocurrieron y sostuvo, procurando como en efecto consiguió, la seguridad y mayor beneficio de los intereses de los Indios [...]". '. Seguidamente, y ante la renuncia del oficial primero de Salta, Francisco Vicente y Zebrián, Atienza fue nombrado para dicho cargo por de Paula Sanz. ${ }^{10}$ En 1789 surgió la posibilidad de un traslado a Oruro con el mismo cargo pero hasta donde sabemos no se llevó a cabo. El traslado de un oficial de la Corona generalmente indicaba un ascenso. En este caso, podemos corroborarlo comparando los sueldos de los oficiales primeros de ambas cajas: en Oruro era de 815 pesos anuales entre 1784 y 1804 , mientras que en Salta, en 1785, era de 500 pesos y en 1789 , de 594 pesos (Gavira Márquez, 2011). ${ }^{11}$

En 1793 pretendió, infructuosamente, el puesto de contador de la ciudad de Santa Fe de la Vera Cruz. Mencionaba este último pedido que la conducta y habilidad de Atienza merecían un premio pues dejarlo como subalterno significaba que su trabajo era poco puntual. Además, señalaba que por no dejar el real servicio, el oficial se encontraba "en un país extraño", sin parientes ni conocidos y sin la posibilidad de socorrer y reintegrar a su madre viuda y sus siete hermanos lo que le habían suplido, consumiendo sus legítimas, para pagarle los viajes y sostenerlo con decencia. ${ }^{12}$ No parece que la situación de Atienza fuera extraordinaria: la inmovilidad geográfica regía los destinos de quienes elegían el camino del servicio en la Hacienda. A pesar de que los ascensos no llegaran, un ejercicio administrativo de este tipo se percibía como una participación a escala local de la soberanía real que honraba a su beneficiario y favorecía a su linaje; los honores que recibía de ella bastaban para satisfacerlo y hacer atractivos esos oficios. ${ }^{13}$ Por otro lado, los oficiales de Real Hacienda, muy en particular los de las reales cajas, eran interlocutores obligados y privilegiados de todos los actos económicos de su respectiva circunscripción (Bertrand, 2011).

A pesar de que a comienzos del siglo XVIII se llevó a cabo un proceso de profesionalización en el sector de los servidores de la Hacienda que arrojó como resultado la adquisición, por parte de los oficiales, de competencias técnicas difíciles de suplir, en la búsqueda de un cargo un oficial real difícilmente escapaba al sistema de protecciones y recomendaciones. La primacía que se atribuía a la experiencia obligaba a encontrar un protector que estuviese en posición de ofrecer la oportunidad de adquirir esa primera práctica (Bertrand, 
2011). Nos resulta evidente que Atienza se había preparado de alguna manera para ejercer cargos en la Hacienda y que alguien propició su ingreso a ella, pues hasta donde tenemos conocimiento no pertenecía a un linaje al servicio de la administración, por lo menos en la región. ${ }^{14}$ Y respecto de personas que lo promocionaran o protegieran, sólo tenemos el dato de los nombramientos que le otorgó Paula Sanz.

\section{La comisión de Atienza en Tucumán: el convidado de PIEdRa}

La carrera en la administración era una oportunidad a la hora de integrar grupos influyentes y también un punto de encuentro y desencuentro entre los diferentes grupos y redes sociales. Atienza pudo vivir en carne propia todas esas opciones. En 1795 fue comisionado para hacerse cargo de la tesorería de Tucumán, ya que había quedado vacante por el fallecimiento de su teniente, don Martín Ángel Varón. ${ }^{15}$ En esos casos era necesario subvenir un reemplazo temporal antes de que el proceso de designación instituyera a un nuevo oficial, ya que la muerte del implicado significaba una completa revisión de las cuentas y, en caso necesario, la deducción a expensas de los bienes del difunto.

En su paso por esa tesorería menor, Atienza se encontró con la oposición de algunos vecinos detentadores del poder local y sin el apoyo del subdelegado en funciones. Específicamente, acusó al comandante de armas, Juan Silvestre Deheza y Helgueros, y al alcalde de primer voto, Domingo García, de atacar a sus dependientes:

[...] yendo a una diligencia interesante el unico guarda que hay en esta caxa con dos mozos milicianos que llamo de mi orden, el comandante de las armas don Juan Silvestre Deheza y Helgueros, los ha quitado en medio de la calle con gran estrepito y perjuicio de la Real Hacienda ultrajando al propio tiempo a dicho guarda fundado en que no dio el permiso para citarlos. [...] pocos dias ha el alcalde de primer voto don Domingo García prendio a el mismo guarda sin otro motivo que el de exijirle seis pesos, que yo pagaba por él, y el alcalde no quizo admitirmelos; y aunque sobre ambos pasajes entable recursos ante este subdelegado, todo está hasta el dia sin curso [...]. ${ }^{16}$

Los hechos descriptos por Atienza no fueron anecdóticos ni únicamente simbólicos, ya que los dependientes de la tesorería eran de fundamental importancia para llevar adelante las tareas de las cajas. El mencionado guarda había sido contratado por Atienza y asalariado de su propio peculio "[...] para que cele clandestinas introducciones y tratos ocultos que tanto damnifican al estado [...]". ${ }^{17}$

Los ministros, Gabriel Güemes y Diego Rabaza, apoyaron decididamente a Atienza, no sólo porque consideraron que lo ocurrido contra el guarda causaba perjuicios al erario, sobre todo porque en las pequeñas ciudades se carecía por lo general del auxilio de subalternos, sino también porque entendían que despreciar al ministro subalterno significaba también injuriar la autoridad de los ministros principales y la del gobernador intendente, que dimanaban inmediatamente de la del rey.

Así, solicitaron al gobernador Ramón García y Pizarro que mandara al subdelegado, a quien acusaron de “inacción”, actuar para resolver los maltratos de Deheza y Helgueros y García; y sobre el alcalde de primer voto, resaltaron el hecho de que siendo "profesor del derecho de los más sobresalientes" ignorara el goce de fuero militar que tenía el guarda sólo por ser criado de Atienza. Y agregaron:

Por todo inferimos que el comisionado don Antonio Atienza y los intereses del rey en aquella tesoreria estan absolutamente desamparados [...] y en este caso el perjuicio es visible pues para precaucionarlo no sera jamas bastante aquel solo ministro aunque se vuelba un Argos [...]. ${ }^{18}$

Días después del pedido al intendente, el comerciante Pedro Martínez de Vinueza, enviado por Atienza, informó a los ministros sobre conductas "criminosas" de vecinos y comerciantes de Tucumán que se reunían bajo sentimientos ajenos a la soberana voluntad. Pensaba el teniente tesorero que se estaba planeando algo en su contra y los ministros temieron por su seguridad: 
[...] travaxa vigilante por desterrar abusos, por contener excesos, por dar a la Real Hacienda sus verdaderos valores, [...] porque todo se sugete a la ley y a la razon y es lo mismo que algunos, o ciegos en su ambicion o supinamente ignorantes de sus obligaciones procurarán perturbar, alucinar y confundir, y tal vez (Dios no lo quiera) bengar. ${ }^{19}$

No era la primera vez que estas quejas se presentaban en relación con la situación de la administración de las cajas de Tucumán. En un viaje que el tesorero Güemes realizó a esa ciudad, señaló que en aquel lugar nadie quería encargarse de servir la tesorería y que, en general, la situación de los tenientes era difícil: "Si es activo y vigilante se acarrea el odio general [...] y si es contemplativo se trastorna todo el orden de los negocios de que está encargado [...]" (Güemes, 1982, p. 153). En su momento, el mismo Varón recibió llamadas de atención de parte de los ministros por falta de cuidado en la cobranza de los tributos, morosidad y falta de contemplación en el manejo de la caja. A ello respondió que si ajustaba su trabajo podía ser objeto de graves perjuicios. ${ }^{20}$ Los tenientes no sólo estaban vinculados a los intereses locales sino que además estaban presionados por ellos.

El análisis sobre los tenientes tesoreros de Tucumán y el comportamiento de su elite deben ser contextualizados teniendo en cuenta las características particulares de la ciudad. Señala Gabriela Tío Vallejo (2001) que Tucumán se conformó como ciudad plutocrática y vinculada al comercio; particularmente, en la segunda mitad del siglo XVIII la elite local tucumana presentaba un carácter marcadamente mercantil; el antiguo modelo de encomenderos-mercaderes que había prosperado en siglos anteriores había sufrido una trasformación con el ingreso de comerciantes peninsulares a las filas de la elite (Bascary, 1999; López, 2003). Este grupo acaparó buena parte de los cargos políticos y económicos locales, como el cabildo, estancos, junta de temporalidades, recaudadores de diferentes impuestos, tesoreros, etc. De cara a la sociedad, el honor se encontraba íntimamente asociado al ejercicio de la autoridad. De hecho, el comandante de armas, Deheza y Helgueros, practicaba la actividad comercial y era socio de comerciantes vinculados al consulado de Lima (Saguier, 2004-2010). Por todo lo dicho, no es de extrañar que la presencia de un representante real ajeno a los intereses locales le significara una molestia.

Tradicionalmente, quienes se desempeñaban como tenientes tesoreros pertenecían a la sociedad local: no eran oficiales enviados por la corona desde otros espacios. Según un informe elaborado por el contador Julián Arriaga, en el Tucumán ocupaban esos empleos no los más idóneos sino los que daban más dinero para llegar al cargo (Acevedo, 1965). Esta realidad no escapaba al entendimiento de los ministros, que señalaban el inconveniente de que en las ciudades subalternas la Hacienda fuera manejada “[...] por propios vecinos, quienes ligados entre si hacen causa comun sobre propios intereses [... $]^{21}{ }^{21}$ En las ciudades pequeñas, la intimidad entre comerciantes y oficiales reales era más estrecha y favorecida por el reducido número de habitantes. ${ }^{22}$

Dentro de esta trama de intereses particulares y protecciones de lo local es importante señalar que el fallecido teniente Miguel Ángel Varón también había desarrollado prácticas comerciales ${ }^{23}$ y formaba parte de una parcialidad política que incluía al subdelegado Escobar y que no había tenido las mejores relaciones con Deheza y Helgueros. Pero, aunque Deheza y Helgueros y Escobar no formaran parte de los mismos intereses y de hecho hubieran rivalizado por el control del poder, es evidente que ambos se resistieron al control planteado por el tesorero comisionado. ${ }^{24}$

¿Las posibilidades de Atienza para librarse de situaciones difíciles dependían menos de su poder que de su integración en redes que pudieran movilizarse en su favor? El contexto administrativo en el que le tocaba actuar era hostil y sus opositores gozaban de poder y prestigio. Frente a estos inconvenientes, su calidad de foráneo le impedía contar con apoyos sólidos en la ciudad. ${ }^{25}$

Este conflicto debe ser comprendido, además, dentro de los enfrentamientos entre la ciudad de San Miguel de Tucumán en defensa de su autonomía y Salta como capital de la Intendencia. Cuando se implementó la Ordenanza de Intendentes, la elección de Salta como cabeza de intendencia respondió a su situación de preeminencia económica, pero tal jerarquía necesitó ser defendida por sus vecinos, que apelaron a contactos en la Audiencia de Charcas y en la corte para imponerse a otra candidata: San Miguel (Marchionni, 2008: 11). 
La presencia de Atienza en San Miguel de Tucumán generó oposiciones por ser el representante de una Hacienda que, desde Salta, pretendía controlar y ajustar el cobro de los tributos que le correspondían. La guerra interior fue permanente por la resistencia del vecindario tucumano a contribuir con el real erario en los términos planteados por la Corona.

\section{“ENCUENTRos ESCANDALOSOS EN UN PUEBLO DE CORTO VECINDARIO". LA ENEMistad DE LOS OFICIALES REALES CON EL SUBDELEGAdo ViCENTE ESCOBAR}

En 1796 falleció el contador principal Diego Rabaza y el virrey ordenó que Atienza retornara a Salta para servir interinamente dicha contaduría. El traspaso de la caja de San Miguel de las manos de Atienza a las del nuevo teniente tesorero, nombrado por el intendente Pizarro, Joseph Colombres Thames, inició un fuerte conflicto con el subdelegado.

Libros y caudales debían ser entregados al teniente tesorero en presencia del subdelegado y el escribano público y de cabildo, Juan Antonio Porcelo. El escribano pasó por la oficina de hacienda para entregar el expediente de nombramiento y fianzas a Atienza, para que contestara inmediatamente y se diera curso a la posesión de Colombres en el cargo. Pero Atienza expresó que necesitaba tiempo para leer el expediente y reconocerlo como correspondía, por los muchos quehaceres que le daba la Real Hacienda, "[... y yo firmo por decir hallarse embarazado" ${ }^{26}$ Ante esta situación, el subdelegado Escobar conminó al escribano a dirigirse nuevamente, junto con dos testigos, a la casa donde funcionaba la caja para hacer firmar el expediente. Esta vez el oficial se negó a entregar la caja hasta que le fueran realmente significativas las seguridades dadas por el nuevo teniente, y por la cantidad de 10.000 pesos, pues arguyó que, aunque Colombres era de su entera satisfacción, como ministro contador interino era responsable junto con el tesorero Güemes de las resultas de los manejos de Colombres y, por lo tanto, nadie podía forzarlo a hacer la entrega de la caja sin que precedieran los mencionados requisitos. En el decreto de nombramiento del teniente tesorero se enunciaba que los fiadores debían ser "sujetos de arraigo" a satisfacción del subdelegado y del teniente tesorero comisionado; Colombres los había presentado por la suma de 6.000 pesos y Escobar los había recibido solo. ${ }^{27}$

Atienza alertó, además, respecto del subdelegado, que se abstuviera en lo sucesivo de insultar al ministerio de hacienda, con el método de hacerle saber providencias mediante escribano y testigos. En respuesta, Escobar ordenó que, como Atienza ya no tenía absolutamente nada que ver en las cajas, se siguieran las órdenes del nuevo teniente tesorero e informó de esto a los guardas de la caja para que respondieran sólo a Colombres, bajo amenaza de ser castigados si no le obedecían. El escribano debía comunicar esto a Atienza, pero éste lo había amenazado diciendo que "[... si bolvia alli otra vez con los testigos me daria de palos a mi y a los testigos y que havia de coger un trabuco y envestirnos y que de esto diera certificación si quisiese [... ]". ${ }^{28}$

El subdelegado suspendió el envío de intimaciones y acudió directamente al gobernador para denunciar "la declarada desobediencia" y el entorpecimiento que causaba el oficial primero en el traspaso de la caja. Atienza esgrimió en su defensa que, por ser Vicente Escobar deudor de la Real Hacienda y ramo municipal de sisa, por él y su difunto hijo, estaba legítimamente impedido de intervenir en ningún asunto concerniente a la caja.

A raíz de esta situación, la tesorería se había quedado sin guardas, puesto que Escobar los había amenazado con prisión si obedecían las órdenes de Atienza, con lo cual ambos guardas habían abandonado la oficina:

[...] dejando sin custodia los sagrados intereses de Real Hacienda que hay existentes en ella: que la ciudad esté sin resguardo: que el publico se halle escandalizado: y por ultimo que estén arriesgadas y suspensas las cobranzas del erario, las cuentas de fin de año demoradas y los deudores de Real Hacienda insolentados [...]". ${ }^{29}$

Además, Escobar ya no reconocía a Atienza como teniente tesorero. Atienza fue más allá en la disputa y solicitó que Escobar fuera apartado de su cargo: 
El cumulo de atentados y vejamenes irrogados por este subdelegado con sus voluntariedades y reserbados fines particulares, a el ministerio de Hacienda, exijen una completa satisfacción, y el que mirandolo con conmiseración se le releve del empleo que obtiene, por que su misera constitución, su abanzada edad, y su poca inteligencia, no proporcionan al serbicio del rey otra bentaja mas, que entorpecer quanto se pone en sus manos [...]. ${ }^{30}$

Agregó que haría entrega de la caja al nuevo teniente cuando tuviera las cuentas arregladas, postergadas hasta el momento por las disposiciones del subdelegado, y en un día por él señalado. Güemes, como ya lo mencionamos, apoyaba a Atienza incondicionalmente contra el subdelegado y recordaba que desde sus primeros suspiros lo había tenido como opositor. No ahorró en descalificaciones para describirlo ante el gobernador y pedir también él su alejamiento del cargo:

[...] Escovar no está capaz de desempeñar, ni la mas tribial función de sus encargos por su abanzada edad octogenaria, por su notoria insolvencia, que le constituye en el mas lamentable estado, y por sus pocos conocimientos en el basto delicado manejo de la Real Hazienda que pide prontitud de espiritu, instrucción no comun y muy particular desinteres calificado, y presencia de animo continuado para contrarrestar las hascechansas de los muchos que intentan su perjuicio y disipación, y por tanto sera conveniente al Real Servicio se le releve dejandole solo para que se encomiende a Dios en los pocos días de vida que le restan. ${ }^{31}$

Es crudo el enfrentamiento entre el oficial de hacienda y el subdelegado, cuyo poder en las ciudades era muy importante. A pesar de ser todos representantes del rey, queda claro que unos lo son más que otros pues los subdelegados respondían sobre todo a sus particulares intereses locales, al ser vecinos de la sociedad donde actuaban y por lo general estar involucrados en sus actividades mercantiles.

En relación con las fianzas que debía dar Colombres, Güemes aseguró que había pedido que fueran por diez mil pesos y que Escobar, incurriendo en procedimientos abusivos, las había reducido a seis mil. De todas maneras, decidió reducir la fianza a seis mil pesos por conocer su buena conducta, pero alertando que no bastaba la aprobación sola de Escobar sobre la calidad de dichas fianzas pues desconfiaba del subdelegado.

Finalmente, el gobernador intendente, Ramón García Pizarro, resolvió que se recibiera a Colombres luego de que las fianzas fueran aprobadas por Atienza y que quedaban sin efecto las providencias en contrario tomadas por el subdelegado.

\section{Compadres, PATRones, AFIANZADORES}

Por red de sociabilidad se entiende el conjunto permanente o temporal de vínculos de naturaleza diversa que unen a los individuos entre sí. Esas relaciones constituyen una verdadera organización social que engloba a la totalidad de los individuos implicados. En el Antiguo Régimen la red de sociabilidad asociaba dos tipos de relaciones personales: las desarrolladas en el seno familiar, de tipo lateral, y las clientelares, de tipo vertical. Las redes no podían ser, entonces, algo dejado al azar de los encuentros ocasionales (Bertrand, 2011).

Era natural que cierto tipo de vínculos se construyeran dentro del espacio de trabajo. Antonio Atienza apadrinó a dos hijos de Benito Ortiz de la Torre, ${ }^{32}$ empleado subalterno en la Real Hacienda, también de origen peninsular. ${ }^{33}$

Por fuera de su espacio laboral lo encontramos como apoderado de Gregorio de Zegada, oriundo de Granada, devenido en importante miembro de la elite regional, con un fuerte poder político y económico, a la sazón subdelegado de Jujuy. ${ }^{34}$

En 1807 asumió como tesorero interino ante la muerte del propietario Gabriel Güemes. Fueron sus fiadores importantes comerciantes de la ciudad: Francisco Xavier Figueroa, Mateo Gómez Zorrilla, Juan Nadal y Guarda y Pedro José de Ibazeta. ${ }^{35}$ Figueroa e Ibazeta eran cuñados y ambos se dedicaban al comercio mular. Francisco Xavier era hijo de Antonio de Figueroa, quien procedente de Córdoba forjó una ascendente carrera social y económica basada en el comercio mular y en la integración a la elite local mediante el matrimonio con María del Carmen Toledo Pimentel. Pedro Ibazeta, oriundo de Vizcaya, se había afincado 
previamente en Córdoba y estaba casado con Vicenta Figueroa. El comercio colonial no se comprende si no se tienen en cuenta sus vinculaciones espaciales, que excedían ampliamente el marco de una ciudad (Mata, 1991). Gómez Zorrilla y Juan Nadal y Guarda se desempeñaban como comerciantes de efectos de Castilla; los cuatro pertenecieron al cabildo y desempeñaron diversos cargos en distintos momentos de sus vidas (Marchionni, 2000).

A mediados del siglo XVIII se había producido una reactivación del espacio mercantil andino, enlazada en parte a la recuperación de la actividad minera altoperuana cuyos centros debieron ser abastecidos de alimentos e insumos. En ese espacio, Salta se erigió como estación de tránsito gracias a sus campos aptos para la invernada de mulas y como centro redistribuidor de efectos de Castilla introducidos por Buenos Aires; el comercio mular se estableció como la actividad más relevante de la región (Mata, 1991). El contexto permitió a vecinos de Salta conseguir cierta prosperidad gracias a la actividad mercantil, así como la radicación y el paso de importantes comerciantes vinculados con casas comerciales de Cádiz, cuyos agentes instalados en Buenos Aires intentaban captar los mercados altoperuanos (Mata, 2005). Relacionado con esto, podemos afirmar, junto con Bertrand, que en general los fiadores eran comerciantes volcados a actividades que se adecuaban a los rasgos predominantes de la economía regional. La superposición casi perfecta entre los intereses económicos de los fiadores y las deducciones que los oficiales de la Real Hacienda debían aplicar a esos mismos agentes económicos permite entrever los arreglos sobre los que desembocaba ineluctablemente la sociedad que se establecía en el marco de las fianzas. ${ }^{36}$ Tanto el padre de Francisco Xavier, Antonio de Figueroa, como Juan Nadal y Guarda, fueron fiadores del tesorero Güemes, lo cual muestra una intención sistemática de generar un lazo con quien ocupara el cargo, independientemente de la persona.

En el Antiguo Régimen el individuo se concebía inserto en un tejido de vínculos familiares que procuraba protección; las relaciones construidas a partir del matrimonio eran de suma importancia y ello se reflejaba en el campo de la vida económica y política. Los oficiales elegidos desde Madrid carecían por lo general de vínculos conocidos en la región a la que estaban destinados; por lo tanto, se supone que tenían la necesidad de construir un nuevo entorno familiar y social en América que significara una puerta de acceso a la sociedad local.

En el siglo XVIII se produjo una revalorización de lo peninsular y del servicio real por la consideración en que lo tuvo la Corona en relación con las nuevas políticas de organización administrativa. Ser oficial real entrañaba un honor importante e implicaba que podía contar con influencias políticas, además de tener un cargo permanente; los oficiales reales, en general, constituían uno de los pocos grupos económicamente seguros en la colonia, con un sueldo fijo y con la certeza de que sólo una gran irresponsabilidad acarrearía sus despidos (Arnold, 1991). Por otra parte, ser peninsular significaba no llevar sobre la cabeza el estigma de la posibilidad del mestizaje con indígenas o negros. Todas estas características hacían de un oficial real un buen candidato para contraer matrimonio. Sin embargo, Antonio Atienza jamás se casó, dato no menor a la hora de pensar este tipo de vínculo como uno de los más importantes en cuanto a relaciones establecidas con la comunidad local, y posibilidades de ascenso y promoción.

\section{LOS CAMBIOS EN LA REVOLUCIÓN}

El inicio de la revolución de 1810 generó diversas respuestas políticas a lo largo del territorio del Virreinato del Río de la Plata y prontamente derivó en guerra, estado de excepción por excelencia. Dada la instauración de la Junta de Buenos Aires en mayo de 1810 y la posterior convocatoria de Cabildo abierto en Salta, el ayuntamiento se pronunció por la causa de la revolución con el acuerdo de los ministros de Real Hacienda, a la sazón Nicolás Villacorta y Ocaña y Antonio Atienza en su calidad de tesorero interino (Solá, 1947).

Sin embargo, la adhesión al levantamiento de mayo distó de ser unánime. Mientras gran parte de la sociedad salteña se mostró indiferente, la facción realista contó con un número considerable de adeptos, manifiestos o encubiertos, los suficientes para alentar al ejército real acerca de las posibilidades de recuperar estos territorios. 
Esto fue claro para el gobernador intendente nombrado por Buenos Aires, Feliciano Chiclana, quien informó a la Junta que una considerable parte del vecindario era de opinión contraria a la revolución (Mata, 2000). Por su parte, a principios de 1812, encontrándose Belgrano en Salta, expresaba en diversas comunicaciones la animosidad existente hacia el Ejército Auxiliar después de las derrotas sufridas en junio de 1811, la gran deserción entre la tropa y la falta de conocimiento de la población acerca de los motivos de la revolución. Al mismo tiempo, en los valles calchaquíes se conformaba bajo el mando del hacendado Juan José Aramburu un escuadrón de caballería alistado en las tropas reales (Chaile, 2019).

Desde los inicios, desde Buenos Aires se intentó garantizar la fidelidad de gobernantes y de las principales autoridades administrativas. En esta línea, la Asamblea de 1813 decretó que todos los españoles europeos que gozaran de algún oficio fueran excluidos de este si no obtenían la carta de ciudadanía; redibujaba así la situación de quienes antaño estaban seguros respecto de su lugar en la sociedad. La carta de ciudadanía actuaría a modo de salvoconducto, pretendiendo distinguir entre metropolitanos favorables al nuevo orden y hostiles a él (Tejerina, 2018). La Asamblea rechazó ingentes solicitudes y el abanico de peninsulares que, teniendo algún cargo eclesiástico, administrativo o militar, debieron dejar sus empleos fue amplio. ${ }^{37}$ En julio de ese año, el gobernador Feliciano Chiclana comunicó a los ministros de la Tesorería que Atienza quedaba separado de esas cajas porque la Asamblea no había tenido por conveniente concederle el título de ciudadano. ${ }^{38}$

Villacorta y Ocaña, el contador de las cajas, estuvo en desacuerdo con la separación de Atienza y mediante varios informes pidió que su colega fuera restituido en su cargo, para lo cual resaltaba sus cualidades:

[...] quede el expresado don Antonio Atienza sugeto de conocida honradez, buenas costumbres, de suma inteligencia en el manejo, y que hasta el presente se la ha notado ni de palabra, ni de obra, según la opinión general cosa alguna que se oponga, a la sagrada causa que defendemos $[. ..]{ }^{39}$

Atienza había sido separado de su cargo de oficial primero y de su interinato como tesorero de las cajas, y en su lugar había sido nombrado quien añoraba desde hacía mucho tiempo dicho puesto: don Lorenzo Fernández de Baldivieso. Fernández de Baldivieso contaba con una carrera administrativa al servicio de la Hacienda: hasta donde sabemos, comenzó empleado como oficial segundo o de sisa para pasar luego a ocupar el cargo de alcalde de la aduana. Ya en septiembre de 1810 había solicitado que se lo nombrase como oficial primero, aunque el cargo no estaba vacante: pertenecía a Atienza, quien interinamente se hallaba ocupado como tesorero (Aramendi, 2009a). Villacorta y Ocaña tampoco estuvo de acuerdo con el nombramiento de Fernández de Baldivieso, sobre quien expresó no tener los conocimientos necesarios para desempeñarse en el cargo (Aramendi, 2020). El concepto vertido por el contador sobre los conocimientos de Fernández de Baldivieso debe ser matizado si tenemos en cuenta que pocos años antes, al momento de crearse la Aduana en Salta, Villacorta y Ocaña, como contador, y el tesorero Gabriel Güemes fueron los propulsores del ascenso de Baldivieso de oficial segundo a alcalde de la Aduana. Asimismo, alabaron del dependiente la hermosura de su letra y su capacidad para formar estados y llevar los libros (Aramendi, 2009a, p. 193). Por otro lado, la idea de que Fernández de Baldivieso ocupase el cargo de oficial primero era una intención de vieja data: cuando en 1789 se esperaba que Atienza fuera trasladado a Oruro, para ocupar su vacante se había pensado en Baldivieso.

Mientras tanto, Atienza seguía prestando servicios en la Tesorería. En diciembre, el general Belgrano, a cargo del Ejército del Norte, mediante orden enviada a la Tesorería decretó la expulsión del oficial hacia la ciudad de Santiago del Estero. ${ }^{40}$ Nuevamente Villacorta y Ocaña hizo oír su postura:

La expulsión de Atienza a Santiago del Estero, indudablemente, tiene su origen en la calidad de europeo. Entre estos no todos son iguales, algunos tienen mejor carácter, mejor índole, otros conocimientos, y son capaces de convencerse. El Ministerio comprehende en Atienza uno de estos, y por consiguiente sale de garante de su conducta, que jamás será perjudicial, ni al sistema en general, ni al Ejército del mando de Vuestra Excelencia. ${ }^{41}$ 
Los pedidos e informes de Villacorta y Ocaña redundaron, finalmente, en un resultado favorable para Atienza. A fines de 1813 Chiclana autorizó su reingreso al ejercicio de las funciones que desempeñaba pero sin investidura alguna y Fernández de Baldivieso fue jubilado. ${ }^{42}$ Evidentemente, las palabras de Villacorta fueron escuchadas por Chiclana, con quien había viajado en su momento a Potosí para ordenar el Banco de San Carlos. De todas maneras, en 1814 el nuevo contador de Salta era Pedro Cevallos y Atienza continuaba en el cargo de oficial primero encargado.

El otorgamiento de la ciudadanía dependía de la resolución de la Asamblea; claramente, resultaba brumosa su adhesión a la causa revolucionaria. No había contraído matrimonio, importante paso a la hora de vincularse con la sociedad local. Por otra parte, había requerido su traslado por lo menos en dos oportunidades a otros espacios del virreinato y en 1793, cuando llevaba casi diez años de presencia en el Río de la Plata, se decía de él que estaba en un "país extraño".

El caso de Atienza refleja la compleja situación que vivían los oficiales reales peninsulares que no habían obtenido la requerida carta de ciudadanía y al mismo tiempo, la otra cara de la moneda que tensaba los deseos más radicales del gobierno, que finalmente tuvo que admitir la presencia de estos dudosos adeptos a la revolución porque no contaba con cuadros administrativos competentes. Es decir, los reglamentos y decisiones del gobierno se vieron superados por prácticas y situaciones concretas como la que señalamos (Salvatto y Banzato, 2013). Claramente, no todos los peninsulares estuvieron sospechados de realistas: muchos de ellos fueron fervientes revolucionarios y otros tantos siguieron desempeñándose en distintos ámbitos de la administración sin ningún tipo de problema, como por ejemplo Nicolás Villacorta y Ocaña.

\section{"BAJO EL AMPARO DEL SANTO DE MI NOMBRE..."}

En abril de 1815 Atienza dictó su testamento y pidió ser enterrado en el convento de San Francisco o en su cementerio, y con dicho hábito, de cuya orden era tercero. ${ }^{43}$ Otorgó la libertad a sus dos esclavas y a las dos hijas de una de ellas, y les dejó dinero para sus vestuarios y para que pudieran trabajar en "agencias propias de mujeres". Declaró como herederos universales a sus tres hermanos y dos hermanas en caso de que siguieran con vida, pero sólo concedió derecho de representación a los hijos de su hermana Juana y de su hermano Juan Antonio. Mencionó que había sido albacea testamentario del peninsular Diego Estaquero, fallecido en la ciudad de Salta, mientras que sus albaceas fueron, en España, sus hermanos José Pedro y Juan Antonio y su primo José María Gómez; y en Salta, Pedro José de Ibazeta y su mujer, Vicenta Figueroa y Francisco Asencio de Lezama. La función del albacea era importantísima ya que de él dependía la satisfacción de la voluntad del difunto en todo lo que éste le encomendara, en una época en la que la vida cotidiana giraba en torno a la Iglesia, la religión, la muerte y la necesidad de recibirla cristianamente. Así, se evidencia la estrecha relación de Atienza con Ibazeta, quien había sido su fiador en 1807. Pocos días después de elaborar el testamento, Atienza se vio compelido a reemplazar a sus albaceas en Salta, dado que se planteó la duda sobre si, al ser peninsular, podían ser sus albaceas también "españoles ultramarinos". Pero este cambio ¿estaba dado solamente por el origen de Ibazeta y Lezama?

Como mencionamos con anterioridad, Ibazeta pertenecía a una importante familia de estancieros y comerciantes de mulas. En los últimos años de la colonia el comercio mular era el fundamento de la actividad económica de la jurisdicción, la principal compañía comercializadora era la formada por José Gómez Rincón y Domingo Olavegoya, y su apoderado en Salta era José Pedro de Ibazeta. Estos tres agentes y su parentela manifestaron de manera constante su lealtad al rey y colaboraron con los realistas cuando éstos se instalaban en Salta. Francisco Asencio de Lezama también era comerciante, poseedor de tiendas en Salta.

Bajo dominio revolucionario, los peninsulares fueron objeto de sospecha por parte de las autoridades y sometidos a contribuciones forzosas por el hecho de ser "españoles peninsulares" o "europeos". El gobernador Domingo García impuso en mayo de 1812 el primer empréstito a ser solventado por europeos. Gravitó en él la intención de gravar a los dueños de las principales fortunas, quienes, por su origen, en principio podían 
ser considerados sospechosos. En el caso de Salta, esas fortunas, en el ámbito urbano, correspondían a los comerciantes peninsulares (Marchionni, 2019). Esta situación era la de Ibazeta y Lezama, que figuraron en la lista de los que debían pagar en ese entonces y también en la de 1815 (poco tiempo después de que Atienza forjara su testamento), cuando tuvieron que contribuir con un empréstito forzoso en su calidad de "españoles europeos". 44

A partir de 1810 ambos dejaron de ocupar cargos capitulares, de la misma manera que muchos otros comerciantes peninsulares (Marchionni, 2019), hasta el interregno realista de agosto de 1812 a febrero de1813, cuando el general Pío Tristán tomó la ciudad, ya que supuestamente tanto Ibazeta como Lezama formaron parte del cabildo que juró la Constitución de Cádiz; ${ }^{45}$ los regidores elegidos para la festividad señalada lo fueron entre personas distinguidas por su "inalterable adhesión al Soberano" (Chaile, 2019). Señala Marchionni (2019) que la entrada del ejército de Pío Tristán visibilizó el partido realista en Salta y Jujuy. En ambas ciudades se conformaron nuevos cabildos tras la emigración de los llamados "patriotas" de reconocida lealtad. No sabemos cuál fue el comportamiento de Atienza durante las ocupaciones realistas de Pío Tristán en 1812/1813 y Pezuela en 1814 pero logró mantenerse en la Hacienda.

Así, "para no viciar su última resolución”, los mencionados albaceas y Vicenta Figueroa fueron reemplazados por el sacerdote José Gabriel de Figueroa y por el alcalde de primer voto Miguel Francisco Aráoz. ${ }^{46}$ Figueroa, hermano de Vicenta, tuvo una destacada actuación en el proceso revolucionario y Aráoz ${ }^{47}$ era cabildante en 1815, con lo cual ambos eran probados "patriotas".

En definitiva, los albaceas en los que Atienza confió en primera instancia podían ser sindicados como partidarios del rey, lo cual identifica al propio oficial con esa tendencia y confirma el resquemor de la Asamblea a otorgarle la ciudadanía y a dejarlo ejercer las funciones para las cuales estaba calificado.

\section{REFLEXIONES FinALES}

Atienza llegó a América como oficial de la Corona. No tenemos conocimiento de que su familia tuviera una historia al real servicio, pero sí de que apoyaron materialmente la carrera de Antonio. Respecto de las relaciones que construyó, podemos observar que sobre todo tuvieron que ver con su identidad "peninsular" y su actividad como oficial de la Hacienda. Fueron redes que de alguna manera lo acercaron, por un lado, al poder económico y político de la ciudad de Salta con las posibilidades que ello implicaba, y al mismo tiempo lo enfrentaron con los vecinos de la ciudad de Tucumán. El hecho de que no contrajera matrimonio con una mujer del lugar lo excluyó de una pertenencia plena a la sociedad local. Por otra parte, a pesar de conformar las filas de los representantes del rey, ingresó a éstas en un puesto subalterno, lo cual lo situaba en una posición no demasiado ventajosa.

Su trayectoria nos ubica en dos momentos de tensión. En primer lugar, en el contexto de las reformulaciones institucionales planteadas por las reformas borbónicas cuando, como comisionado en San Miguel de Tucumán, se enfrentó a los grupos de la elite local que, abroquelada, e incluyendo al subdelegado del intendente, defendió sus intereses particulares. Y, en segundo lugar, en la revolución de 1810, cuando su situación sufrió un cimbronazo, pues sospechado de realista, vio peligrar su cargo en la administración a partir de la denegación de la carta de ciudadanía. Sin embargo, su experticia fue difícil de rechazar para los nuevos detentadores del poder político.

A través de Atienza miramos el cambiante mundo finicolonial en los márgenes de la monarquía. Llegado a América con un cargo situado en la capital del Virreinato del Río de la Plata, vio torcido el rumbo de su carrera frente a la supresión de su puesto y el traslado a una intendencia lejana a los centros económicos y de poder político. La región del Tucumán constituía, sin embargo, un espacio intensamente mercantilizado, vinculado al alto Perú y al puerto de Buenos Aires; y Salta, como capital de Intendencia, era una ciudad de importancia notoria comparada con el resto de las ciudades de la antigua gobernación, con excepción de Córdoba, y con 
voluntad de control respecto de sus subordinadas, lo cual observamos en las participaciones de Atienza en la Hacienda tucumana. Ese lugar de frontera ocupado por el Tucumán fue central también en el momento de la revolución, ya que la posición estratégica de la Intendencia de Salta entre el litoral atlántico y el Perú la convertiría en territorio de vanguardia.

Atienza representa a muchos que dejaron sus lugares de origen para dedicar su vida a un oficio y que en ese recorrido generaron una fuerte identificación con su empleo. Su trayectoria nos permite visualizar las prácticas en la administración de la Hacienda tucumana, intuir modalidades de recaudación y administración, sus especificidades y sus lógicas, contenidas dentro de una organización política mayor en franca transformación.

\section{FUENTES DOCUMENTALES}

ABHS, Fondos de Gobierno, Caja 7, años 1785-1786.

ABHS, Fondos de Gobierno, Caja 9, años 1786-1787.

ABHS, Fondos de Gobierno, Caja 12, año 1789.

ABHS, Fondos de Gobierno, Caja 13, años 1789-1790

ABHS, Fondos de Gobierno, Caja 15, año 1795.

ABHS, Fondos de Gobierno, Caja 16 A, años 1797-1799.

ABHS, Fondos de Gobierno, Caja 27 B, año 1810.

ABHS, Fondos de Gobierno, Caja 30 A, año 1813.

ABHS, Fondos de Gobierno, Caja 30 B, año 1813.

ABHS, Protocolos Notariales, Escribano Ignacio Molina, año 1815.

ABHS, Protocolos Notariales, Escribano José Antonio Molina, año 1801.

ABHS, Protocolos Notariales, Escribano Marcelino Silva, año 1806.

AGN (2016). Homenaje al Bicentenario de la declaración de la Independencia 1816-2016, Fondos Documentales, Asamblea General Constituyente (1813-1815), Congreso Soberano de las Provincias Unidas del Rio de la Plata (1816-1820). Buenos Aires: AGN, Ministerio del Interior, Obras Públicas y Vivienda.

AHT, Sección Administrativa, vol. 5, años 1767-1770.

Family search, Argentina, Salta, registros parroquiales, 1634-1972.

Güemes, L. (1982). Güemes documentado. Buenos Aires: Plus Ultra. Tomo 7.

Méritos y servicios de don Antonio Atienza y Picazo, oficial de las reales cajas de Salta (1947). Boletín del Instituto de San Felipe y Santiago de Estudios Históricos de Salta, 5(20), 81-84.

\section{RefERencias}

Acevedo, E. (1965). La Intendencia de Salta del Tucumán en el virreinato de Río de la Plata. Mendoza: UNCuyo.

Aramendi, B. (2008). Gabriel Güemes Montero: funcionario ilustrado y vecino respetable. Andes, 19, 159-182.

Aramendi, B. (2009a). En lo más bajo de la administración colonial: guardas y receptores de la Real Hacienda. Salta, siglo XVIII. Anuario del Centro de Estudios Históricos "Prof. Carlos Segreti", 9, 183-197.

Aramendi, B. (2009b). El Ramo de Bulas de Santa Cruzada en el Tucumán colonial. Diálogo Andino, 33, 59-74.

Aramendi, B. (2011). Burocracia y sociedad colonial. Las reformas borbónicas y su impacto en Salta (1750-1810) (Tesis doctoral, inédita). Salta: Universidad Nacional de Salta.

Aramendi, B. (2020). El Resguardo de la Aduana durante el proceso revolucionario en Salta (1810-1817). Revista de Historia de América, 159, 79-108. https://doi.org/10.35424/rha.159.2020.633

Arnold, L. (1991). Burocracia y burócratas en México, 1742-1835. México: Grijalbo. 
Barriera, D. (2014). Corregidores sin Corregimientos: Un caso de mestizaje institucional en Santa Fe del Río de la Plata durante los siglos XVII y XVIII. Revista de Estudios Histórico-Jurídicos, 36, 245-269.

Bascary, A. M. (1999). Familia y vida cotidiana. Tucumán a fines de la colonia. Tucumán: Universidad Pablo de Olavide-UNT.

Bertrand, M. (2011). Grandeza y miseria del oficio. Los oficiales de la Real Hacienda de la Nueva España, siglos XVII y XVIII. México: FCE/El Colegio de Michoacán/Centro de Estudios Mexicanos y Centroamericanos/Embajada de Francia/Instituto de Investigaciones Dr. José María Luis Mora.

Bertrand, M. y Moutoukias, Z. (Eds.) (2018). Cambio institucionaly fiscalidad: Mundo hispánico, 1760-1850. Madrid: Casa de Velázquez.

Bourdieu, P. (1997). La ilusión biográfica. En P. Bourdieu, Razones prácticas. Sobre la teoría de la acción (pp. 74-83). Barcelona: Anagrama.

Caño Ortigosa, J. L. (2007). La Real Hacienda en venta: los oficiales reales de Guanajuato (1665-1775). En J. Ruiz Rivera y A. Sanz Tapia (Coords.), La Venta de Cargos y el Ejercicio del Poder en Indias (pp. 139-157). León: Universidad de León.

Cornejo, A. (1946). Historia de Güemes. Buenos Aires: ESPASA-CALPE.

Chaile, T. (2019). Adhesiones políticas y festividades cívico-religiosas de revolucionarios y realistas en la intendencia de Salta durante los desplazamientos de ejércitos en pugna (1812-1813). Andes, 2(30), 1-38. Recuperado de ht tp://www.icsoh.unsa.edu.ar/numeros-andes/andes-2019-30-vol-2/

Das, V. y Poole, D. (2008). El estado y sus márgenes. Etnografías comparadas. Cuadernos de Antropología Social, 27, $19-52$.

Dedieu, J. P. (2000). Procesos y redes. La historia de las instituciones administrativas de la época moderna, hoy. En J. L. Castellano, J. P. Dedieu y V. López-Cordon (Eds.) (2000). La pluma, la mitra y la espada. Estudios de Historia Institucional en la Edad Moderna (pp. 13-30). Madrid: Marcial Pons.

Dubet, A. y Solbes Ferri, S. (Coords.) (2015). Monográfico "Actores políticos y actores sociales en el gobierno de la Hacienda”. Tiempos modernos, 8(30). Recuperado de http://www.tiemposmodernos.org/tm3/index.php/tm/i ssue/archive

Dubet, A. y Solbes Ferri, S. (Coords.) (2016). La construcción de la hacienda hispánica en el largo siglo XVIII. Madrid: Casa de Velázquez.

Emilliani, J. (1994). Manual de administración indiana. Córdoba: edición del autor.

Gavira Márquez, C. (2011). El escándalo de las quiebras en la Real Hacienda. 1784-1804. Revista de Estudios Bolivianos, 8, 161-183. Recuperado de http://bsj.pitt.edu

Imízcoz, J. M. (1996). Comunidad y red social, y élites. Un análisis de la vertebración social en el Antiguo Régimen. En J. M. Imízcoz (Dir.), Elites, poder y red social. Las élites del País Vasco y Navarra en la Edad Moderna (pp. 13-50). Bilbao: Universidad del País Vasco.

Imízcoz, J. M. (2002). Introducción. Actores sociales y redes de relaciones: reflexiones para una historia global. En J. M. Imízcoz (Dir.), Redes familiares y patronazgo. Aproximación al entramado social del Pais Vasco y Navarra en el Antiguo Régimen (siglos XV-XIX) (pp. 19-30). Bilbao: Universidad del País Vasco.

López, C. (2003). Redes de parentesco y poder en la "frontera" de Tucumán: la familia Alurralde. En C. López (Comp.), Familia, parentesco y redes sociales (pp. 139-173). Tucumán: REHPoS, Instituto de Estudios Geográficos, Facultad de Filosofía y Letras, UNT.

Marchionni, M. (2000). Acceso y permanencia de las elites en el poder político local. El cabildo de Salta a fines del período colonial. Cuadernos de la Facultad de Humanidades y Ciencias Sociales, 13, 283-306.

Marchionni, M. (2008). Cabildos, territorios y representación política (1810-1825). Buenos Aires: Cuadernos de Trabajo del Centro de Investigaciones Históricas del Departamento de Humanidades y Artes. Serie Investigaciones, 15. Recuperado de https://www.historiapolitica.com

Marchionni, M. (2019). Politica y sociedad en Salta y el norte argentino (1780-1850). Salta: Fondo Editorial Secretaría de Cultura de la Provincia de Salta-ICSOH-EUCASA. 
Mata, S. (1991). Economía agraria y sociedad en los valles de Lerma y Calchaquí. Fines del siglo XVIII. Anuario del IHES, 6, 59-80.

Mata, S. (2000). La guerra de la independencia en Salta y la emergencia de nuevas relaciones de poder. Andes, 13, 1-22.

Mata, S. (2005). Tierray poder en Salta. El noroeste argentino en visperas de la independencia. Salta: CEPIHA, Facultad de Humanidades, UNSa.

Picazo Muntaner, A. (2011). Redes invisibles, cooperación y fraude en el comercio de Manila-Acapulco. Anales del Museo de América, 19, 140-152. Recuperado de https://www.libreria.culturaydeporte.gob.es/libro/anales-delmuseo-de-america-xix 2011_4094/

Quiñónez, M. (2010). Familia y poder. Los Patrón Costas y la conformación de la elite salteña (mediados del siglo XVIII a principios del siglo XX) (tesis doctoral, inédita). La Plata: Universidad Nacional de La Plata, Facultad de Humanidades y Ciencias de la Educación.

Saguier, E. (2004-2010). Genealogía de la tragedia argentina. Auge y colapso de un fragmento de estado o la violenta transición de un orden imperial-absolutista a un orden nacional-republicano (1600-1912). Recuperado de https ://www.er-saguier.org/

Sánchez de Bustamante, T. (1957). Biografias Históricas de Jujuy. Tucumán: UNT, Facultad de Filosofía y Letras.

Solá, M. (1947). Salta (1810-1821). En R. Levene (Dir.), Historia de la Nación Argentina. Desde los orígenes hasta la organización definitiva en 1862. Vol. X (pp. 365-401). Buenos Aires: El Ateneo.

Salvatto, F. y Banzato, G. (2013). Poderes locales y gobierno central ante el cambio de régimen en Buenos Aires: cartas de ciudadanía, cargos públicos y práctica de oficios, 1812-1815. VII Jornadas de Historia y Cultura de América La construcción de las independencias: Documentos, actores y representaciones (2013, Montevideo). Recuperado de http://www.memoria.fahce.unlp.edu.ar/art_revistas/pr.2518/pr.2518.pdf.

Socolow, S. (1987). The Bureaucrats of Buenos Aires, 1769-1810: Amor al Real Servicio. Durham: Duke University Press.

Tejerina, M. (2018). “Dispersos, emigrados y errantes...”. La expulsión territorial en la década revolucionaria. Boletín del Instituto de Historia Argentina y Americana Dr. Emilio Ravignani, 48, 13-47.

Tío Vallejo, G. (2001). Antiguo Régimen y liberalismo. Tucumán, 1770-1830. Tucumán: Cuadernos de Humanitas, Facultad de Filosofía y Letras, UNT.

Wayar, A. (2010). “El Tucumán tardocolonial en la Real Hacienda. 1770-1809”. XXII Jornadas de Historia Económica, Río Cuarto (Córdoba),Asociación Argentina de Historia Económica,21 a 24 septiembre. Recuperado de http://www.aahe.fahce.unlp.edu.ar/jornadas-de-historia-economica/xxii-jornadas-de-historia-economica-ri o-cuarto-2010/ponencias/wayar.pdf/view

Zamora, R. (2017). Casa poblada y buen gobierno. Oeconomía católica y servicio personal en San Miguel de Tucumán, siglo XVIII. Buenos Aires: Prometeo.

\section{Notas}

1 José María Imízcoz se refiere con esta expresión a un modo específico de acercarse a la realidad social a través de la microhistoria, la prosopografía o la biografía (1996, p. 16).

2 Es menester considerar la importancia de la organización del Antiguo Régimen en términos de comunidades o cuerpos sociales y de redes de vínculos personales, en las que los hombres y las mujeres estaban adscriptos por vínculos de pertenencia a formaciones colectivas de diversa índole, formalizadas legalmente e institucionalizadas como tales (Imízcoz, 1996, p. 20).

3 Desde la prosopografía clásica, las obras de Susan Socolow (1987) sobre el Río de la Plata y Linda Arnold (1991) para México han encarado el estudio del heterogéneo y amplio grupo de los servidores de la Corona, incluyendo a los oficiales de la hacienda. Otros autores abordaron el estudio de los oficiales de hacienda específicamente: Caño Ortigosa (2007) investigó la cuestión de la venta de oficios en las cajas de Guanajuato, Nueva España, mientras que, para el espacio del Virreinato del Río de la Plata, Gavira Márquez (2011) estudió a los oficiales de las cajas de Carangas y Oruro en Charcas, indagando sobre el peso que éstos tuvieron en la sociedad colonial a través del ejercicio de sus cargos. 
4 Señala, asimismo, que para una gran cantidad de espacios periféricos no se conoce con exactitud hasta qué punto operaron las políticas fiscales implementadas por los Borbones, cómo se instrumentaron y qué resultado obtuvieron (Wayar, 2010).

5 También se agregó la Puna como subdelegación. En 1794 se sumó a la Intendencia la recientemente fundada San Ramón de la Nueva Orán y en 1807 se agregó la jurisdicción de Tarija. Córdoba fue elegida cabecera de la otra Gobernación Intendencia y de ella dependieron La Rioja y las ciudades cuyanas de Mendoza, San Juan y San Luis, que hasta entonces habían formado parte de la Capitanía General de Chile.

6 Tenía Antonio cinco hermanos. Dos de ellos, José Pedro y Juan, estudiaron leyes. José Pedro se desempeñó como canónigo de la iglesia de Alcalá de Henares. Antonio fue criado en Cádiz por sus tíos, María de los Dolores Domínguez y Juan Felipe Gómez. Archivo y Biblioteca Históricos de Salta (en adelante ABHS), Protocolos Notariales, Escribano Ignacio Molina, año 1815, Salta, 8 de abril de 1815, fs. 15 a 19.

7 Méritos y servicios de don Antonio Atienza y Picazo, oficial de las reales cajas de Salta (1947). Boletín del Instituto de San Felipe y Santiago de Estudios Históricos de Salta, 5(20), 81-84.

8 Bertrand (2011) señala que, antes de su ingreso al empleo, un gran número de oficiales peninsulares, nombrados para la Nueva España, había desarrollado desde la metrópoli actividades relacionadas con América. Otros habían partido a América mucho antes de su nombramiento en la administración con el propósito de ejercer otros cargos o actividades, mientras que otra fracción contó desde su llegada con la ventaja de ciertos contactos a través de un pariente o protector que ya se encontraba en el lugar.

9 Méritos y servicios de don Antonio Atienza y Picazo, oficial de las reales cajas de Salta (1947). Boletín del Instituto de San Felipe y Santiago de Estudios Históricos de Salta, 5(20), 82.

10 ABHS, Fondos de Gobierno, Caja 7, años 1785-1786. Asunto: Señalamiento de los derechos de media anata que debe satisfacer don Antonio Atienza por el cargo de oficial de primera de la tesorería, Buenos Aires, 6 de diciembre de 1785. Concepción Gavira Márquez (2011) afirma que todos los cargos menores de las cajas eran cargos vendibles, cuestión que, por el momento, y para el espacio que nos ocupa, no podemos refrendar ni rechazar de plano dada la información con la que contamos.

11 ABHS, Fondos de Gobierno, Caja 12, año 1789. Asunto: Comunicación del virrey al gobernador intendente de Salta, Mestre, acerca de los traslados y provisión de cargos en la tesorería de las ciudades de Salta y Oruro, Salta, 20 de abril de 1789.

12 Méritos y servicios de don Antonio Atienza y Picazo, oficial de las reales cajas de Salta (1947). Boletín del Instituto de San Felipe y Santiago de Estudios Históricos de Salta, 5(20) 1947, 81-84.

13 Para Nueva España, señala Bertrand (2011) que la carrera profesional de un oficial real se definía principalmente por su estabilidad geográfica y que la mayoría conocía únicamente el horizonte de su primera afectación.

14 Tenemos conocimiento de la existencia de Francisco Atienza Ibáñez, castellano y justicia mayor del puerto de Cavite en Manila en los últimos años del siglo XVII, y maestre de campo de Filipinas en los primeros años del XVIII. Ocupó un lugar preponderante en la política y comercio de Manila aunque ignoramos los posibles lazos familiares con Antonio (Picazo Muntaner, 2011).

15 Varón había sido comerciante, carretero y capitán de forasteros de la ciudad; acusaba noble origen en el reino de Navarra (Zamora, 2017).

16 ABHS, Fondos de Gobierno, Caja 15, año 1795. Tucumán, 31 de octubre de 1795.

17 ABHS, Fondos de Gobierno, Caja 15, año 1795. Al señor brigadier de los reales ejércitos Ramón García y Pizarro. Salta, 9 de noviembre de 1795.

18 ABHS, Fondos de Gobierno, Caja 15, año 1795. Tesorería General de Salta al señor brigadier de los reales ejércitos don Ramón García y Pizarro. Salta, 14 de noviembre de 1795.

19 ABHS, Fondos de Gobierno, Caja 15, año 1795. Tesorería General de Salta al señor brigadier de los reales ejércitos don Ramón García y Pizarro. Salta, 14 de noviembre de 1795. Las amenazas a los oficiales de la Hacienda por estar encargados de implementar innovaciones, reformas o poner orden en determinados espacios no fueron extraordinarias aunque en ocasiones llegaron a hacerse realidad. A principios del siglo XVIII el superintendente de alcabalas de Puebla, a causa de su nueva administración recibió promesas de muerte (Bertrand, 2011). El despojo de la administración de la Renta de Tabacos a la ciudad de La Rioja despertó el repudio de ciertos grupos locales, que en un informe al gobernador intendente Sobremonte expresaron que los oficiales reales eran mal vistos no solo por su condición de europeos sino también por la calidad de sus empleos en recaudar los ramos de la Real Hacienda; dichos oficiales se contuvieron en ese momento respecto a la recaudación por temor a que ello pudiera causarles persecuciones (Saguier, 2004-2010). Como representantes del rey, los oficiales de Hacienda estuvieron también expuestos. En el contexto del levantamiento de 1781 podemos mencionar la occisión, a manos de los indígenas sublevados, del contador de las cajas de Carangas, Juan Manuel Güemes, que fue ultimado junto al corregidor y otros personajes del pueblo (Gavira Márquez, 2011).

20 ABHS, Fondos de Gobierno, Caja 9, años 1786-1787. Tucumán, 30 de enero de 1787. 
21 ABHS, Fondos de Gobierno, Caja 15, año 1795. Tesorería General de Salta al señor brigadier de los reales ejércitos don Ramón García y Pizarro. Salta, 14 de noviembre de 1795.

22 Esto es señalado por Bertrand (2011) para la ciudad de Veracruz. Con esa intimidad planteada entre los comerciantes y los oficiales reales tropezaron sistemáticamente todos los visitadores que tuvieron que intervenir en ese puerto. El visitador Juan Gárate y Francia, en 1673, redactó un informe en el cual expresaba que uno de los principales obstáculos con los que se enfrentó en su tarea había sido la connivencia y dependencia que los oficiales habían establecido con sus administrados.

23 En 1765 pidió autorización para ingresar mercaderías en Potosí y en 1768 solicitó autorización para introducir petacas con mercaderías a Buenos Aires. Archivo Histórico de Tucumán (en adelante AHT), Sección Administrativa, vol. 5 , años 1767-1770.

24 Las redes sociales no se constituían como realidades fijas, sino que podían variar desde la más estrecha concordia hasta la mayor tensión. En esa polivalencia y variabilidad podían intervenir muchos factores, con lo cual es preciso observar la concordia, el conflicto, la oposición de intereses y la protección en el contexto de las vinculaciones que se producían (Imízcoz, 1996).

25 A pesar de esto, Atienza estableció vínculos con vecinos tucumanos, tal vez establecidos en su estadía en dicha ciudad. En 1801 fue apoderado de don Francisco Pérez Martínez para vender un esclavo de su propiedad. ABHS, Protocolos Notariales, Protocolo 194, Carpeta n 19, Escribano José Antonio Molina, año 1801, Salta, 8 de octubre de 1801, fs. 44 v. a 46 v. Manuela Ávila le otorgó poder para vender un sitio que tenía en Salta. ABHS, Protocolos Notariales, Escribano Marcelino Silva, 1806, Salta, 3 de marzo de 1806.

26 ABHS, Fondos de Gobierno, Caja 16 A, años 1797-1799. Tucumán, 15 de diciembre de 1796.

27 Fueron fiadores de Colombres Thames, obligándose con 600 pesos cada individuo: José de Ojeda, Domingo de Villafañe, Cayetano Fernández de Moure, Manuel Reboredo, Clemente de Zabaleta, Salvador de Alberdi, Cayetano Rodríguez, Miguel Antonio de Alurralde, Valentín de la Lastra y José de la Peña. ABHS, Fondos de Gobierno, Caja 16 A, años 1797-1799. Tucumán, 28 de noviembre de 1796.

28 ABHS, Fondos de Gobierno, Caja 16 A, años 1797-1799. Tucumán, 16 de diciembre de 1796.

29 ABHS, Fondos de Gobierno, Caja 16 A, años 1797-1799. Tucumán, 20 de diciembre de 1796.

30 ABHS, Fondos de Gobierno, Caja 16 A, años 1797-1799. Tucumán, 22 de diciembre de 1796.

31 ABHS, Fondos de Gobierno, Caja 16 A, años 1797-1799. Salta, 29 de diciembre de 1796.

32 Ramón, bautizado el 4 de septiembre de 1797: "Argentina, Salta, registros parroquiales, 1634-1972", en database with images, FamilySearch (https://familysearch.org/ark:/61903/1:1:XNCL-ZZB: 9 March 2018), Ramón Ortiz de la Torre, 1797. José María, bautizado el 9 de diciembre de 1801: "Argentina, Salta, registros parroquiales, 1634-1972", en database with images, FamilySearch (https://familysearch.org/ark:/61903/1:1: XNCL-66D: 9 March 2018), Benito Ortiz in entry for José María Ortiz, 1801.

33 Benito Ortiz de la Torre llegó a Salta en 1783 como criado de Joseph González de Prada, contador de las cajas. Por medio del vínculo del compadrazgo estrechó relaciones con su jefe y paisano, el tesorero Gabriel Güemes. También a través de este parentesco espiritual se vinculó con el comerciante de efectos de Castilla y afianzador de mulas Antonio Tejada y con el reconocido comerciante de mulas santafesino Francisco Candiotti. Probablemente, el propio Benito practicó ciertas actividades comerciales (Aramendi, 2009 a).

34 ABHS, Fondos de Gobierno, Caja 13, 1789-1790, Asunto: Testimonio de un expediente seguido por don Antonio de Atienza como apoderado de don Gregorio de Zegada, solicitando 3000 pesos del Ramo de Sisa para la manutención de los indios de la Reducción de Zenta, a su cargo. Salta, 18 de febrero de 1790. Zegada se dedicaba al pingüe comercio mular y ocupaba diversos oficios. Desempeñó el cargo de tesorero de cruzada durante doce años, desde el gobierno de Gerónimo Matorras hasta el de Andrés Mestre, de quien fue fiador para que pudiera servir el empleo. La excelente relación de Zegada con Mestre fue notable: este lo nombró gobernador de armas en 1778 y le encomendó la fundación de la reducción del Zenta cuando se desempeñaba como alcalde de ler voto en Jujuy. En 1779 le otorgó merced de tierras en el Chaco y cuando se instaló el sistema de Intendencias Mestre lo nombró subdelegado en Jujuy (Aramendi, 2009 b; Sánchez de Bustamante, 1957).

35 ABHS, Fondos de Gobierno, Caja 27 B, año 1810, Carpeta: Diciembre. Salta 16 de noviembre de 1807, escribano Isidro Matorras.

36 Para Nueva España Bertrand (2011), señala que la profesión de los fiadores era predominantemente el comercio; luego, miembros de la administración y militares. Podemos corroborar esta situación para el espacio del Tucumán (Aramendi, 2011).

37 Respecto de los empleos de Hacienda, el Tribunal de Cuentas, en 1818, solicitaba que se cubrieran varios puestos que habían quedado vacantes como consecuencia de la aplicación del decreto que privaba a los españoles europeos que no hubieran obtenido carta de ciudadanía, de sus empleos (Archivo General de la Nación, en adelante AGN, Homenaje al Bicentenario de la declaración de la Independencia 1816-2016, Fondos Documentales, Asamblea General Constituyente (1813-1815), Congreso Soberano de las Provincias Unidas del Río de la Plata (1816-1820), p. 260. 
38 ABHS, Fondos de Gobierno, Caja 30 B, año 1813. Carpeta: 1443. Salta, 17 de julio de 1813.

39 ABHS, Fondos de Gobierno, Caja 30 A, año 1813.

40 Belgrano no dudó en desterrar de Salta y Jujuy a opositores a la causa revolucionaria, a diferentes espacios: San Carlos, Tucumán, Cuyo, Santiago del Estero. El confinamiento de opositores radicaba en la necesidad de cortar el apoyo logístico que pudieran brindar a realistas: provisión de recursos, transmisión de información, incorporación de hombres a sus fuerzas (Chaile, 2019). Marcela Tejerina plantea un interesante panorama sobre la expulsión territorial en épocas revolucionarias a manera de herramienta en la lucha por el poder, práctica de disciplinamiento utilizada ya en la época de los Borbones. A lo largo de la década revolucionaria, la elección de determinados lugares para cumplir con la expulsión se debía a que estaban alejados de los centros más importantes de la resistencia española, de decisión o de conflicto (Tejerina, 2018).

41 ABHS, Fondos de Gobierno, Caja 30 A, año 1813. Carpeta: diciembre. Salta, 24 de diciembre de 1813.

42 ABHS, Fondos de Gobierno, Caja 30 A, año 1813. Carpeta: diciembre, 1441. Salta, 17 de diciembre de 1813.

43 ABHS, Protocolos Notariales, escribano Ignacio Molina, año 1815, Salta, 8 de abril de 1815. Sara Mata (2005, p. 209) señala que las familias con cierto ascenso social, durante el siglo XVIII, adherían con frecuencia a la Orden Tercera de San Francisco. A la hora de testar, el tesorero Güemes también rogó ser enterrado con cordón y escapulario de dicha Orden Tercera (Aramendi, 2. Aramendi, B: Güemes Montero, Andes 19, p. 174.)

44 La mujer de Lezama, Úrsula Quiñónez, también figura entre los que entregaron dinero por los empréstitos forzosos de 1811 y 1815 (Cornejo, 1946).

45 En el listado de cabildantes que juraron la Constitución, Mercedes Quiñonez (2010) incluye a Pedro de Ibazeta y no a Francisco Lezama; por su parte, Cornejo (1946), a la inversa, menciona a Lezama y no a Ibazeta.

46 ABHS, Protocolos Notariales, escribano Ignacio Molina, año 1815, Salta, 28 de abril de 1815.

47 La familia Aráoz arribó a la ciudad de San Miguel durante el siglo XVIII, ejerció un importante peso político y social y se proyectó en las luchas por la independencia y la conformación provincial de Tucumán (López, 2003). 